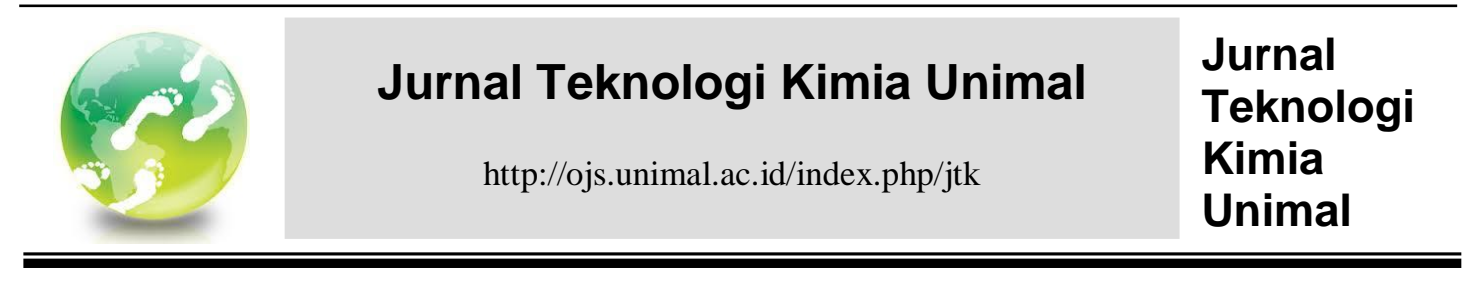

\title{
Simulasi Kontrol PID pada Boiler Sistem Tenaga Uap
}

\author{
Indah Diah Pratiwi, Wusnah, Nasrul ZA* \\ Jurusan Teknik Kimia, Fakultas Teknik, Universitas Malikussaleh \\ Kampus Utama Cot Teungku Nie Reuleut, Muara Batu, Aceh Utara - 24355 \\ *Korespondensi: mhdtk@unimal.ac.id
}

\begin{abstract}
Abstrak
Kontrol PID (Proportional Integrated and Differential) merupakan salah satu jenis kontroler yang paling banyak digunakan di dunia industri. Luasnya penggunaan kontroler ini dilatarbelakangi oleh beberapa hal, salah satunya adalah dalam banyak kasus telah terbukti menghasilkan unjuk kerja relatif memuaskan. Boiler merupakan alat yang sangat penting pada sebuah industri karena steam yang dihasilkan biasanya digunakan untuk power plant dan listrik yang dihasilkan digunakan untuk mengoperasikan peralatan lain dan digunakan untuk kebutuhan proses industri. Tujuan dari penelitian ini adalah mencari waktu terbaik kontrol PID dalam merespon gangguan dengan setting nilai Kc, Ti dan $T d$. Penelitian ini menggunakan simulasi Hysys mode dynamic kontroler dengan menentukan PV (Process Variabel) dan OP (Output Target Object), ditentukan nilai $P V$ maximum dan PV minimum, dengan memvariasikan nilai $\mathrm{Kc}, \mathrm{Ti}$, Td dan temperatur setpoint $\left(270^{\circ} \mathrm{C}, 275^{\circ} \mathrm{C} 280^{\circ} \mathrm{C}, 285^{\circ} \mathrm{C}, 290^{\circ} \mathrm{C}\right)$. Berdasarkan dari hasil pengujian yang telah dilakukan maka diperoleh waktu tercepat kontrol PID dalam merepon gangguan yaitu pada nilai $\mathrm{Kc}=0$,7; $\mathrm{Ti}=1 ; \mathrm{Td}=0$ dengan waktu rata-rata selama 1,170417 menit. Variasi nilai Kc, Ti dan Td tidak mempengaruhi besarnya heat flow yang dibutuhkan boiler.
\end{abstract}

Kata Kunci: $\quad$ Gangguan, Heat Flow, Set point, Temperatur, Waktu

\begin{abstract}
PID control is one of the most widely used types of controllers in the industry. The wide use of this controller is motivated by several things, one of which is in many cases has been proven to produce relatively satisfactory performance. Boilers are a very important tool in the industry because the steam generated is usually used for power plants and the electricity generated is used to operate other equipment and is used for industrial process needs. The purpose of this study was to find the best time of PID control in responding to interference with setting values of $K c$, $\mathrm{Ti}$, and $\mathrm{Td}$. This research uses Hysys mode dynamic controller simulation by determining PV (Process Variable) and OP (Output Target Object), specified maximum $P V$ and $P V$ value, by varying $K c$, Ti, Td and setpoint temperature. Based on the results of the tests that have been done then obtained the fastest time control PID in call disturbance that is at value $K c=0.7 ; \mathrm{Ti}=1 ; \mathrm{Td}=0$ with an average time of 1.170417 minutes. The variation of $K c$, Ti and Td values does not affect the amount of heat flow required by the boiler.
\end{abstract}


Keywords: $\quad$ Disturbance, Heat Flow, Set point, Temperature, Time

\section{Pendahuluan}

Steam merupakan salah satu hasil pengolahan unit utilitas yang sangat berpengaruh pada setiap industri, steam biasanya digunakan untuk proses pada pabrik maupun digunakan pada unit power plant. Pengoperasian peralatan yang digunakan pada banyak industri menggunakan listrik yang dihasilkan oleh steam turbin yang ada di pabrik tersebut. Steam yang digunakan untuk menggerakkan sudu-sudu turbin merupakan steam yang dihasilkan oleh boiler, sehingga boiler sangat berpengaruh terhadap listrik yang dihasilkan oleh turbin, karena jika steam yang dihasilkan oleh boiler mengalami fluktuasi akan mengakibatkan ketidakstabilan besarnya listrik yang dihasilkan oleh turbin dan mengakibatkan tidak maksimalnya pengoperasian alat yang ada pada industri tersebut, sehingga perlu adanya alat kontrol yang dapat menjaga agar steam yang dihasilkan oleh boiler memiliki suhu yang konstan untuk setiap produksi steam.

Pada penelitian ini kontroler yang akan digunakan adalah kontrol PID (Proportional Integral Derivative), sampai saat ini kontrol PID (Proporsional Integral Derivative) merupakan satu-satunya strategi yang paling banyak diadopsi pada pengontrolan variabel proses di industri. Kepopuleran PID sebagai komponen kontrol proses dilatar belakangi terutamakarenastruktur yang sederhana tetapi aplikasinya luas. Masalah utama dalam perancangan kontrol PID adalah tuningnya (penentuan nilai $\mathrm{Kc}, \mathrm{Ti}, \mathrm{Td}$ ). Ada beberapa metode yang dapat digunakan untuk menentukan tiga parameter tersebut yaitu dengan Metode Trial and Error, Metode Ziegler-Nichols, Metode Cohen-Coon, Metode Comparison. Metode yang akan digunakan pada penelitian ini adalah Metode Trial and Error.

\section{Tinjauan Pustaka}

\section{Water Tube Boiler}

Pada water tube boiler, air umpan boiler mengalir melalui pipa-pipa masuk kedalam drum. Air yang tersirkulasi dipanaskan oleh gas pembakar membentuk steam pada daerah uap dalam drum. Boiler ini dipilih jika kebutuhan steam dan tekanan steam sangat tinggi seperti pada kasus boiler untuk pembangkit 
tenaga.Water tube boileryang sangat modern dirancang dengan kapasitas steam antara $4.500-12.000 \mathrm{~kg} / \mathrm{jam}$, dengan tekanan sangat tinggi. Proses pengapian terjadi diluar pipa, kemudian panas yang dihasilkan memanaskan pipa yang berisi air dan sebelumnya air tersebut dikondisikan terlebih dahulu melalui economizer, kemudian steam yang dihasilkan terlebih dahulu dikumpulkan di dalam sebuah steam-drum. Sampai tekanan dan temperatur sesuai, melalui tahap secondary superheater dan primary superheater baru steam dilepaskan ke pipa utama distribusi.

\section{Kendali PID}

Masalah mendasar sistem kontrol adalah tuning atau penalaan, yaitu menemukan nilai parameter yang tepat agar PV (Process Variable) dapat cepat mengejar harga SP (Set Point). Penambahan kontroler PID akan memperbaiki performansi sistem pengendalian. Pada aksi kontrol $\mathrm{P}$, mempunyai arti bahwa besarnya aksi kontrol sesuai dengan besarnya error dengan faktor pengali tertentu. Kelemahan dari aksi ini adalah terdapat steady state error yaitu output mempunyai selisih terdapat set point. Aksi kontrol integral (I) akan menghilangkan steady state error, artinya output sistem akan selalu mengejar set point sedekat mungkin. Aksi kontrol integral sering disebut automatic reset control. Kelemahan aksi kontrol integral adalah terjadinya osilasi sehingga mengurangi kestabilan sistem. Aksi kontrol (D) derivatif sering disebut rate control karena kecepatan perubahan error sebanding dengan sinyal kontrol. Artinya apabila ada perubahan error, maka sinyal kontrol beraksi. Aksi kontrol ini memberikan respon terhadap perubahan sinyal error dan mampu mengoreksinya sebelum error bertambah besar. Aksi kontrol ini mampu mengantisipasi error, mempercepat respon sistem dan meningkatkan stabilitas sistem. Kelemahan dari aksi ini adalah terdapat steady steate error karena error konstan tidak akan menghasilkan sinyal kontrol (sistem yang sudah steady tidak menghasilkan aksi kontrol walaupun jauh dari set point).

Aksi kontrol PID merupakan gabungan aksi kontrol dengan penambahan Proporsional, Integral dan derivatif secara bersamaan, yang akan menghasilkan performansi serta keuntungan gabungan ketiganya. PID mempunyai karakteristik 
reset kontrol dan rate kontrol yaitu meningkatkan respon dan stabilitas sistem serta mengeliminasi steady state error.

Persamaan kontrol PID dalam bentuk Laplace:

$\mathrm{U}(\mathrm{s})=\mathrm{K}_{\mathrm{p}}\left(\mathrm{E}(\mathrm{s})+\frac{1}{\mathrm{TiS}} \mathrm{E}(\mathrm{s})+\mathrm{T}_{\mathrm{DSE}} \mathrm{s}(\mathrm{s})\right)$

\section{Metodologi Penelitian}

Penelitian ini menggunakan Software Aspen Hysys V8.8. Tahapan-tahapan yang perlu dilakukan adalah:

1. Membuat model steady state sistem tenaga uap, flow chart dapat steady state dapat dilihat pada Gambar 1.

2. Mengubah model steady state menjadi mode dynamic, flow chart dapat dilihat pada Gambar 2.

3. Membuat model kontrol PID dan melakukan tuning $\mathrm{Kc}, \mathrm{Ti}$ dan $\mathrm{Td}$ pada sistem. Flow chart dapat dilihat pada Gambar 2 dan Gambar 3.

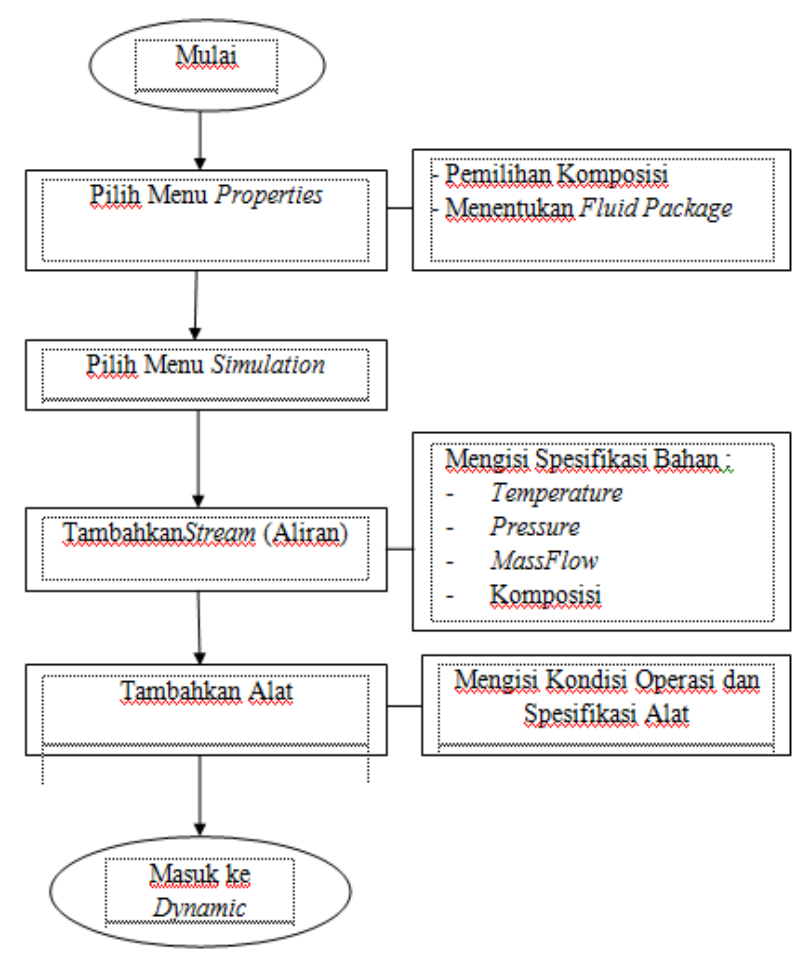

Gambar 1. Bagan Tahapan Penelitian (Steady State). 


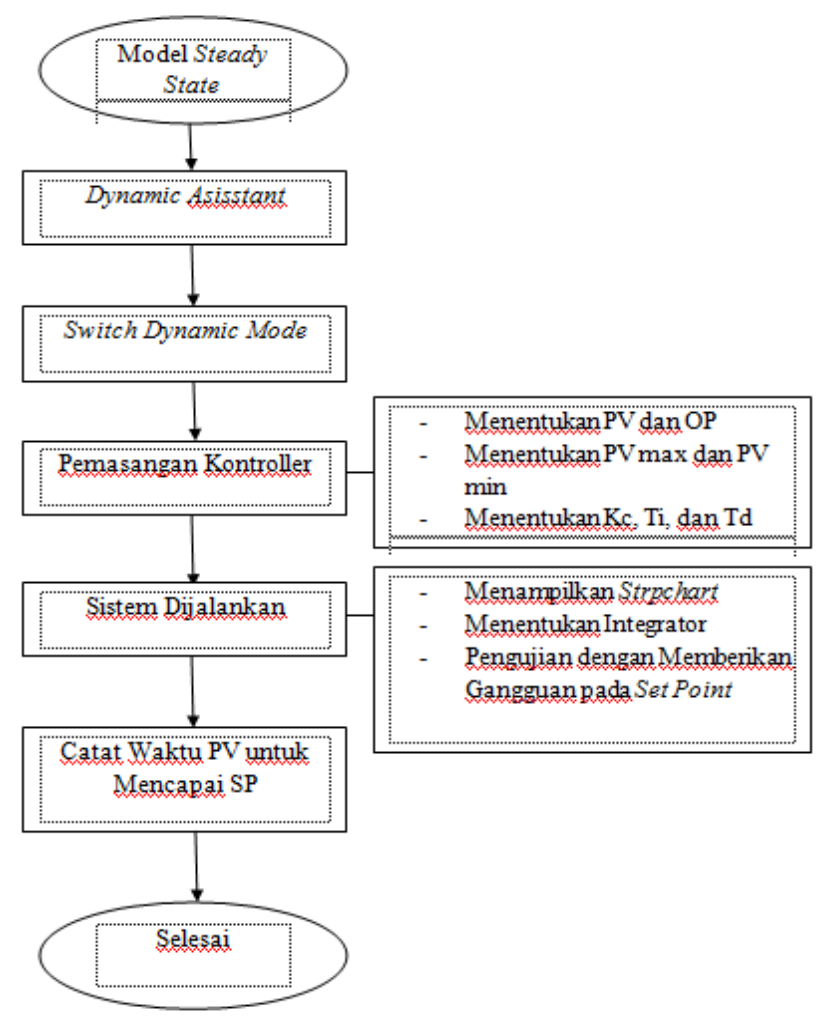

Gambar 2. Bagan Tahapan Penelitian (Dynamic).

\section{Hasil dan Pembahasan}

Pengujian dilakukan untuk melihat respon waktu dari model kontrol dengan memvariasikan nilai setpoint pada range temperatur $(270 ; 275 ; 280 ; 285$; dan $290^{\circ} \mathrm{C}$ ). Berdasarkan dari hasil penelitian maka akan dibahas 1 waktu terbaik dari 25 run yang telah dilakukan. Hasil pengujian dapat dilihat pada Tabel 1.

Tabel 1. Hasil Pengujian Kontrol PID dengan nilai $\mathrm{Kc}=0,7 ; \mathrm{Ti}=1$; $\mathrm{Td}=0$

\begin{tabular}{|c|c|c|c|c|c|c|}
\hline \multirow{2}{*}{ Suhu } & \multicolumn{3}{|c|}{ Parameter Tunning } & \multirow{2}{*}{$\begin{array}{l}\text { Waktu } \\
\text { (Menit) }\end{array}$} & \multirow{2}{*}{$\begin{array}{l}\text { Heat Flow } \\
(\mathrm{kJ} / \mathrm{s})\end{array}$} & \multirow{2}{*}{$\begin{array}{c}\text { Bukaan } \\
\text { Valve } \\
(\%)\end{array}$} \\
\hline & Kc & $\mathrm{Ti}$ & $\mathrm{Td}$ & & & \\
\hline $280-285$ & \multirow{7}{*}{0,7} & \multirow{7}{*}{1} & \multirow{7}{*}{0} & 0,978 & 13535 & 75,20 \\
\hline $285-280$ & & & & 1,104 & 13457 & 74,76 \\
\hline $280-290$ & & & & 1,323 & 13616 & 75,64 \\
\hline $290-280$ & & & & 1,135 & 13457 & 74,76 \\
\hline $280-275$ & & & & 0,823 & 13380 & 74,33 \\
\hline $275-280$ & & & & 1,542 & 13457 & 74,76 \\
\hline $280-270$ & & & & 0,917 & 13304 & 73,91 \\
\hline
\end{tabular}




\begin{tabular}{llll}
\hline $270-280$ & 1,542 & 13457 & 74,76 \\
\hline
\end{tabular}

\subsection{Pengaruh Suhu Setpoint dan Bukaan Valve terhadap Heat Flow}

Pengujian suhu pada aliran steam keluar boiler sangat bergantung pada heat flow di boiler. Hubungan antara suhu $\left({ }^{\circ} \mathrm{C}\right)$ terhadap heat flow $(\mathrm{kJ} / \mathrm{s})$ dapat dilihat pada Gambar 3.

Dari Gambar 3 dapat dilihat bahwa pada suhu $270^{\circ} \mathrm{C}$ membutuhkan heat flow sebesar $13304 \mathrm{~kJ} / \mathrm{s}$, suhu $275^{\circ} \mathrm{C}$ membutuhkan heat flow sebesar $13380 \mathrm{~kJ} / \mathrm{s}$, suhu $280^{\circ} \mathrm{C}$ membutuhkan heat flow sebesar $13457 \mathrm{~kJ} / \mathrm{s}$, suhu 285 membutuhkan heat flow sebesar $13535 \mathrm{~kJ} / \mathrm{s}$, dan pada suhu $290^{\circ} \mathrm{C}$ membutuhkan heat flow sebesar 13616 kJ/s. Dari Gambar 3 juga diketahui bahwa semakin tinggi suhu steam yang diinginkan maka akan semakin besar pula heatflow yang dibutuhkan. Dari hasil pengujian yang telah dilakukan variasi nilai $\mathrm{Kc}, \mathrm{Ti}, \mathrm{Td}$ tidak mempengaruhi besarnya nilai heatflow yang dibutuhkan oleh sistem.

Penelitian ini diatur oleh valve agar proses berlangsung sesuai dengan yang diinginkan. Temperatur yang diinginkan atau SP yakni $280^{\circ} \mathrm{C}$, buka tutupnya valve dikendalikan oleh suatu Temperature Indicator Controller (TIC). Temperatur yang berasal dari proses sebelumnya dideteksi oleh suatu sensor. Data dari sensor dibaca oleh transmitter, kemudian diubah olehnya menjadi suatu sinyal yang dimengerti oleh controller. Data dari transmitter dikirimkan ke TIC kemudian datanya digunakan untuk dibandingkan dengan set point sehingga didapatkan pengontrolan bukaan valve dan temperatur yang diinginkan. Valve yang digunakan bertipe ATO (Air to Open). Fungsi control valve adalah mengatul laju steam. Prinsipnya adalah bertindak sebagai penyempitan variabel (variable restriction) dalam perpipaan proses. Sehingga semakin besar bukaan, maka laju steamnya juga semakin besar.

Berdasarkan gambar 4 dapat diketahui bahwa besarnya bukaan valve dan heat flow untuk setiap nilai $\mathrm{Kc}$,Ti dan Td adalah sama. Semakin besar bukaan valve maka semakin besar pula heatflow karena semakin besarnya suatu valve terbuka maka mengartikan bahwa laju alir yang keluar juga akan semakin besar. Nilai $\mathrm{Kc}, \mathrm{Ti}$, dan Td tidak mempengaruhi perubahan bukaan valve maupun heat 
flow melainkan hanya mempengaruhi cepat atau lambatnya kontrol PID dalam merespon setiap gangguan.

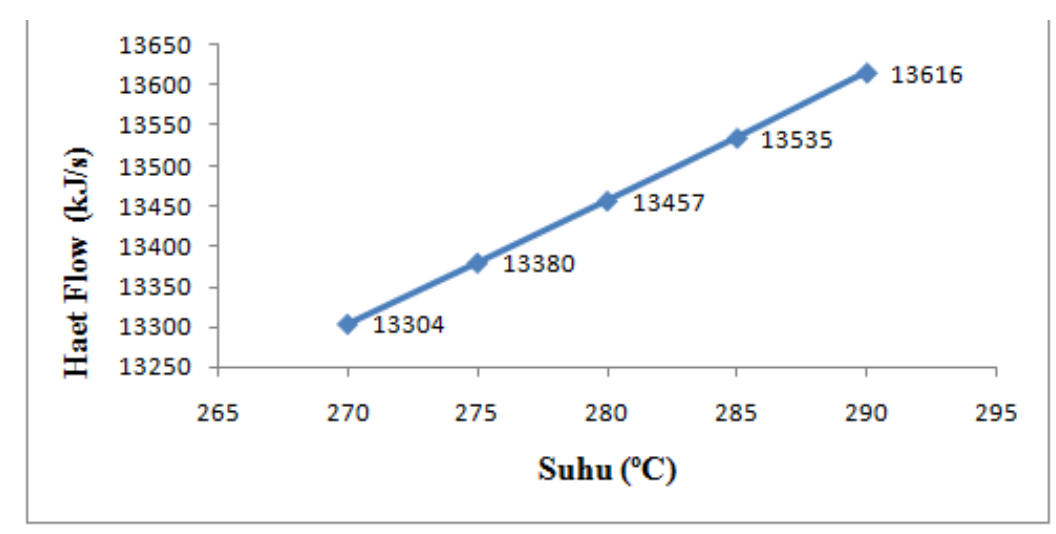

Gambar 3. Grafik Hubungan Suhu $\left({ }^{\circ} \mathrm{C}\right)$ terhadap Heat Flow $(\mathrm{kJ} / \mathrm{s})$

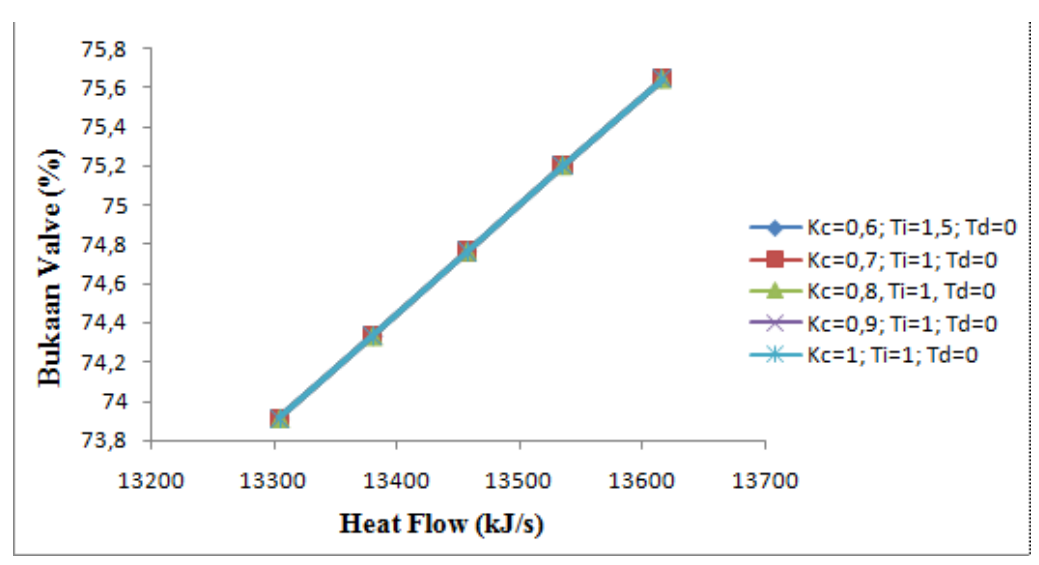

Gambar 4. Grafik Hubungan antara Bukaan Valve dengan Heat Flow

\subsection{Pengaruh Parameter Tunning dengan Waktu Respon Kontrol PID}

Pengaruh nilai Kc, Ti dan Td dengan waktu kontrol PID dalam merespon gangguan dapat dilihat pada Gambar 5. Berdasarkan gambar 5 dapat diketahui bahwa waktu tercepat kontrol PID dalam merespon gangguan dengan memvariasikan setpoint pada range temperatur $\left(270^{\circ} \mathrm{C}, 275^{\circ} \mathrm{C}, 280^{\circ} \mathrm{C}, 285^{\circ} \mathrm{C}\right.$, $290^{\circ} \mathrm{C}$ ) yaitu pada hasil pengujian kontrol $\mathrm{PID}$ dengan nilai $\mathrm{Kc}=0,7 ; \mathrm{Ti}=1 ; \mathrm{Td}=0$ dengan waktu rata-rata 1,170417 menit kontrol PID untuk merespon gangguan 
dan mengembalikan garis Present Value (PV) mengikuti garis Setpoint (SP). Berdasarkan faktor karakteristik dari kontrol PID, jika nilai Kc kecil maka pengontrol proporsional hanya mampu melakukan koreksi kesalahan yang kecil sehingga akan menghasilkan respon sistem yang lambat, jika nilai Kc diperbesar mencapai nilai yang berlebihan maka akan mengakibatkan sistem bekerja tidak stabil atau respon akan berisolasi. Namun apabila pemilihan nilai Ti yang sangat tinggi justru dapat menyebabkan respon transien yang tinggi sehingga dapat menyebabkan sistem tidak stabil. Sedangkan apabila nilai Td ditingkatkan, maka dapat meningkatkan stabilitas sistem dan mengurangi overshoot (Setiawan, 2008). 


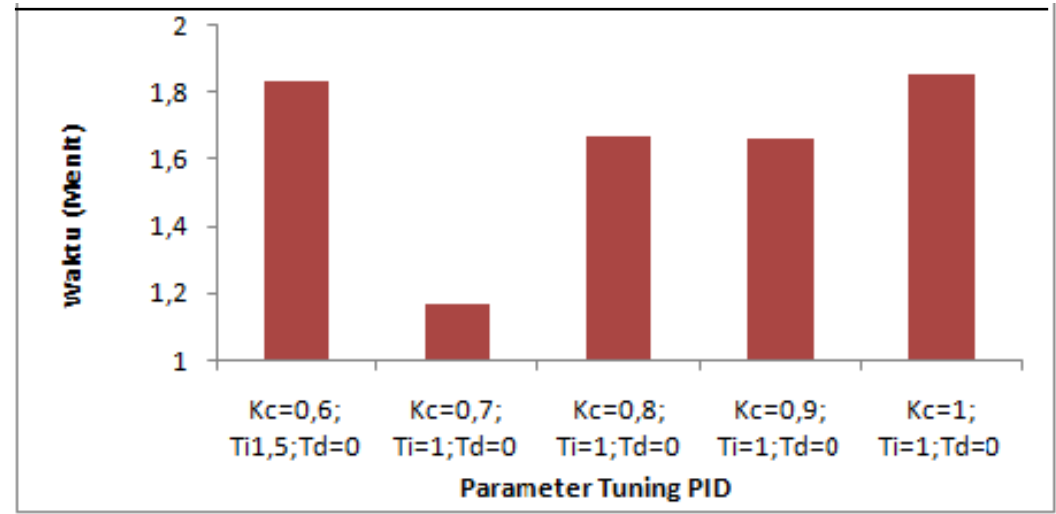

Gambar 5. Pengaruh Nilai Parameter Tuning PID dengan Waktu Kontrol PID dalam Merespon Gangguan

Hasil pengujian model PID pada tabel 1 dengan menggunakan nilai parameter $\mathrm{Kc}=0,7, \mathrm{Ti}=1$ dan $\mathrm{Td}=0$. Pengujian model PID membutuhkan penalaan (tuning) untuk mengatur agar control valve (final control element) merespon error. Masalah penyetelan kontroler proporsional (Kc) adalah sifatnya yang selalu menghasilkan offset. Nilai Kc lebih besar daripada nilai lainnya dikarenakan untuk mengurangi offset. Akan tetapi nilai Kc yang terlalu besar akan menyebabkan sistem cenderung tidak stabil (terjadi osilasi) sedangkan apabila nilai Kc terlalu kecil akan menyebabkan penyimpangan variabel proses (PV) proses terlalu besar. Karena Kc menghasilkan offset maka perlu ditambahkan kendali integral yang berfungsi untuk menghilangkan offset. Nilai Ti yang terlihat pada gambar 6(b) bernilai 1. Sama halnya dengan Kc, nilai Ti yang terlalu besar akan menyebabkan sistem berosilasi dan apabila terlalu kecil akan mengakibatkan overshoot. Kemudian setelah dilakukan tuning pada $\mathrm{Kc}$ dan $\mathrm{Ti}$ respon waktu yang didapatkan sudah bagus yaitu mencapai 1 menit. Oleh karena itu tidak lagi ditambahkan nilai Td untuk lebih mempercepat respon, karena berdasarkan pada penelitian yang telah dilakukan jika ditambahkan nilai Td maka sistem akan menjadi tidak stabil (error). 


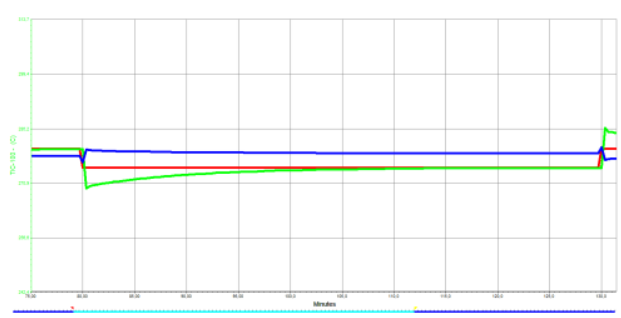

(a)

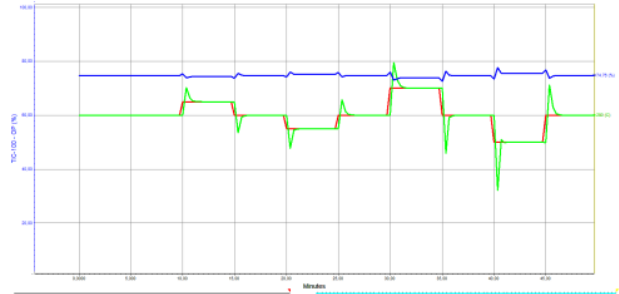

(b)

Gambar 6. Grafik hasil pengujian model PID (a) Sebelum dilakukan tuning parameter PID, (b) Setelah dilakukan tuning parameter PID

(Keterangan Gambar: $\square$ Garis proses variabel (PV) $\square$ Garis setpoint (SP), Uaris bukaan valve (OP).

Berdasarkan gambar 6(a) dapat dilihat bahwa sebelum dilakukan tuning parameter PID yaitu menginput nilai Kc, Ti dan Td, waktu yang dibutuhkan PV (Process Variabel) untuk mencapai SP (Setpoint) sangat lama, sedangkan berdasarkan gambar 6(b) hasil pengujian model PID terlihat adanya hubungan antara Set Point (SP), Process Variabel (PV) dan bukaan valve (OP). SP adalah nilai variabel proses yang diinginkan. PV adalah besaran yang menyatakan keadaan proses dan OP adalah controller output yang sebelumnya diubah dulu oleh transducer menjadi sinyal pneumatik untuk mengatur bukaan control valve sehingga didapatkan temperature yang diinginkan. Terlihat grafik SP cenderung tetap. Grafik PV bergerak naik dan turun menyamakan nilainya dengan SP. Perubahan naik turunnya PV berpengaruh terhadap persentase sinyal kontrol (OP). Terlihat waktu respon rata-ratanya 1,170417 menit. Sehingga dari hasil diketahui bahwa dengan nilai $\mathrm{Kc}=0,7, \mathrm{Ti}=1$ dan $\mathrm{Td}=0$ sebuah sistem pengendalian suhu dapat diterapkan untuk mendapatkan waktu yang paling optimal. Waktu yang optimal dapat memperkecil kemungkinan kecelakaan kerja, kerusakan peralatan, dan memperkecil keragaman kualitas dan produktivitas. Sehingga nantinya akan diperoleh kuantitas dan kualitas produk utama (yield) yang maksimum dengan biaya produksi minumum.

Sistem kontrol sangatlah diperlukan disetiap industri, jika sebuah industri tidak menggunakan sistem kontrol maka keseragaman produk akan semakin besar dan mengakibatkan kecilnya keuntungan. Penelitian mengenai kontrol PID untuk 
mencari waktu terbaik dalam merespon gangguan sangatlah diperlukan, apabila sebuah kontrol di industri membutuhkan waktu yang lama untuk merespon gangguan dengan bukaan valve yang besar maka akan menghabiskan energi yang tinggi dan pastinya berpengaruh terhadap keuntungan industri tersebut. Seperti pada industri kelapa sawit apabila sistem kontrol membutuhkan waktu yang lama dalam merespon gangguan pada steam keluaran boiler maka akan semakin banyak bahan bakar yang digunakan dan mempengaruhi keuntungan pada pabrik tersebut. Sebaliknya apabila sistem kontrol dapat merespon gangguan dengan cepat maka tidak akan menghabiskan bahan bakar yang banyak dan lebih menghemat biaya.

\section{Simpulan}

Dari data hasil penelitian dapat diambil beberapa kesimpulan diantaranya, Kesesuaian nilai konstanta-konstanta $\mathrm{Kc}$, Ti, Td dapat mempengaruhi kemampuan dari kontroler untuk merespon gangguan dengan cepat. Waktu rata-rata tercepat dalam merespon gangguan dengan menvariasikan set point (temperatur) yaitu dengan nilai tuning parameter $\mathrm{Kc}=0,7 \mathrm{Ti}=1 \mathrm{Td}=0$ waktu yang dibutuhkan 1,170417 menit.

\section{Daftar Pustaka}

Boiler, A. S. (2009). Pengendalian Suhu Dan Ketinggian Air Pada Boiler Menggunakan Kendali PID dengan Metode Root Locus, III(2), 23-26.

Budiyanto, S. M. R. W. N. E. (2014). Simulasi Kontrol PID untuk Mengatur Putaran Motor AC. Prosiding SNST Ke-5, 23-28.

Handoko. (2015). Model dan Simulasi Kendala Suhu, Kelembaban, dan Amonia pada Boiler Closed House berbasis ON-OFF, PID, Fuzzy Logic dan ANFIS. Model Dan Simulasi Kendala Suhu, Kelembaban, Dan Amonia Pada Boiler Closed House Berbasis ON-OFF, PID, Fuzzy Logic Dan ANFIS.

Johnson, Michael A dan Moradi, Mogammad H (2006). PID Control New Identification and Design Methods. London:Springer.

Kuyvenhoven, N. (2002). PID Tuning Methods An Automatic PID Tuning Study with MathCad. Neil Kuyvenhoven Calvin College ENGR. 315, 1-8. 
Murgai, M P dan Chandra, Ram. (1990): Progress in Energy Auditing and Conversation Boiler Operations. New Delhi. New Age International (P) Limited Publisher.

Ritonga, Y. (2010). Pengendalian Proses kimia. Proses Pengendalian Kimia, II (1), 1-21.

Wicaksono, H. (2004). Analisa Performansi dan Robustness Beberapa Metode Tuning Kontroler PID pada Motor DC, 4(2), 70-78.

Yudho, B. S., Hikmarika, H., \& Dwijayanti, S. (2013). Aplikasi Perbandingan Pengendali P, PI, Dan PID Pada Proses Pengendalian Suhu Dalam Sistem Mini Boiler. Jurnal Amplifier, 3(2), 12-18. 